\title{
Article \\ The Mechanism of the Effect of Pre-Magnetized Butyl Xanthate on Chalcopyrite Flotation
}

\author{
Tingsheng Qiu ${ }^{1,2}$, Liu Yang ${ }^{1,2}$, Huashan Yan ${ }^{1,2,3, *}$, Hongliang Zhang ${ }^{4}$, Lifeng Cui ${ }^{5}$ and Xiaohe Liu ${ }^{6}$ \\ 1 Key Laboratory of Mining Engineering of Jiangxi Province, Ganzhou 341000, China; \\ 9019810001@jxust.edu.cn (T.Q.); yangliu999777@163.com (L.Y.) \\ 2 College of Resource and Environmental Engineering, Jiangxi University of Science and Technology, \\ Ganzhou 341000, China \\ 3 State Key Laboratory of Mineral Processing, Beijing 100000, China \\ 4 Dashan Concentrator, Dexing Copper Mine, Jiangxi Copper Group, Shangrao 334200, China; \\ zh1574045272@163.com \\ 5 Zijin Mining Group Co., Ltd., Longyan 364200, China; jxlgdx999@163.com \\ 6 Henan Province Industrial Technology Research Institute of Resources and Materials, Zhengzhou University, \\ Zhengzhou 450001, China; liuxh@csu.edu.cn \\ * Correspondence: 9120190062@jxust.edu.cn; Tel.: +86-152-977-63712
}

Citation: Qiu, T.; Yang, L.; Yan, H.; Zhang, H.; Cui, L.; Liu, X. The Mechanism of the Effect of Pre-Magnetized Butyl Xanthate on Chalcopyrite Flotation. Minerals 2022, 12, 209. https://doi.org/10.3390/ $\min 12020209$

Academic Editors: Weiguo Xie, Hylke J. Glass and Eiman Amini

Received: 29 December 2021

Accepted: 2 February 2022

Published: 6 February 2022

Publisher's Note: MDPI stays neutral with regard to jurisdictional claims in published maps and institutional affiliations.

Copyright: (C) 2022 by the authors. Licensee MDPI, Basel, Switzerland. This article is an open access article distributed under the terms and conditions of the Creative Commons Attribution (CC BY) license (https:// creativecommons.org/licenses/by/ $4.0 /)$.

\begin{abstract}
In this work, we applied the technology of magnetic treatment to the flotation of chalcopyrite. The mechanism of the effect of pre-magnetized butyl xanthate on chalcopyrite flotation was studied using monomineral flotation tests, adsorption tests, conductivity tests, Fourier transform infrared spectroscopy (FTIR), etc. The monomineral flotation test results showed that, after the magnetization pretreatment of butyl xanthate solution, the chalcopyrite flotation recovery was increased by nearly two percentage points, and the dosage was reduced by $4-10 \mathrm{mg} / \mathrm{L}$ at the same recovery. The adsorption, FTIR, dissolved oxygen, and conductivity test results all showed that the magnetization pretreatment increased the dissolved oxygen content and promoted the oxidation of butyl xanthate to double xanthate with better selectivity to chalcopyrite. An electrochemical analysis showed that the magnetization pretreatment of butyl xanthate reduced the corrosion potential and corrosion current density of chalcopyrite surface and inhibited the self-corrosion process of chalcopyrite surface. The flotation test results of actual copper sulfide ore showed that pre-magnetized butyl xanthate could increase the copper recovery of copper concentrate by 3.06 percentage points and the sulfur recovery of sulfur concentrate by nearly 3 percentage points, and effectively reduce the mutual content of copper and sulfur concentrates.
\end{abstract}

Keywords: magnetization pretreatment; butyl xanthate; chalcopyrite; flotation

\section{Introduction}

Magnetic treatment is a technology that uses a magnetic field to act on non-ferromagnetic fluids to produce certain desired changes in the properties of the material being acted upon, thereby, improving the production effect and use efficiency. Because of its advantages of simple operation and environmental friendliness, this technology has been widely used in the fields of industrial and agricultural production, medical care, and environmental protection [1].

The combination of magnetic treatment and flotation is called magnetized flotation. In recent years, a large number of scholars, both nationally and internationally, have studied the effect of magnetic treatment technology on mineral flotation behavior from the perspectives of magnetic treatment on flotation water, flotation reagents, and slurry solutions [2,3]. Qiu Tingsheng et al. [4,5] found that magnetic treatment could affect the adsorption amount of an agent on a mineral surface, as well as the conductivity and dissolved oxygen of the agent solution, and therefore, strengthened or weakened the adsorption of the agent on the 
mineral's surface. Zhen Wang et al. [6] found that magnetized water increased the absolute value of zeta potential and the contact angle of molybdenite, and helped to inhibit the edge oxidation of molybdenite in water. Wan He et al. [7] used magnetic treatment technology to improve the collection performance of kerosene for molybdenite, and the results showed that the dosage of magnetized kerosene was reduced by nearly $11 \%$ as compared with unmagnetized kerosene. This may be because the magnetization treatment increased the surface tension of kerosene and reduced the kerosene-water interfacial tension, thereby, reducing the particle size of oil droplets and improving the dispersion of kerosene in the slurry. Zhou Wenbo et al. [8] conducted magnetic treatment on a flotation water solution and a sodium oleate solution. They found that both methods could significantly improve the flotation recovery of fine-grained hematite; the effect of magnetized water was greater than magnetized sodium oleate solution. The results of the zeta potential measurement and the thermodynamic calculation of the particle reaction on the mineral surface showed that the magnetic treatment increased the absolute value of the zeta potential on the mineral surface, and promoted the forward reaction of $\mathrm{Fe}^{3+}$ and $\mathrm{Ol}^{-}$, and therefore the collector was more easily adsorbed on the surface of the target mineral. Manouchehri [9] found that magnetic treatment technology could agglomerate the fine particles in the flotation process. He designed the Proflote magnetic conditioning device and applied it to the Garpenberg concentrator. The results showed that the device improved the flotation recovery of valuable fine minerals and increased the economic benefit of the concentrator. The wide application of magnetic treatment technology in improving the flotation index of molybdenum, iron, and other minerals and its considerable application prospects have been demonstrated.

Copper is widely used in electrical, construction, national defense, and other fields, and it is an important strategic metal [10-12]. China is the world's largest copper consumer, but its copper resource reserves only account for $4.28 \%$ of the world's total copper resources [13]. Copper sulfide ore is the main source of copper metal in China [14]. Its characteristics of a low grade, many associated minerals, and complex properties make the sorting difficult [15-17]. This work attempts to apply magnetic treatment technology to the flotation of chalcopyrite, combining monomineral flotation tests, adsorption capacity tests, FTIR, and electrochemical analysis, etc., to study the effect of pre-magnetized butyl xanthate on chalcopyrite flotation. The research results were verified by an actual ore flotation test and can provide theoretical guidance for the efficient flotation of complex and difficult-to-select copper sulfide ore.

\section{Materials and Methods}

\subsection{Samples and Reagents}

The chalcopyrite monominerals were taken from a mine in Jiangxi province. After manually picking out visible impurities and crushing, the particle size products of $-0.074+0.038 \mathrm{~mm}$ were screened and used for the monomineral flotation tests. The chemical analysis results of chalcopyrite are presented in Table 1 . The calculated purity was 95.31\%, which meets the test requirements. The X-ray diffraction (XRD) pattern is shown in Figure 1. The chalcopyrite electrode used in the electrochemical test was cut and polished from selected chalcopyrite monocrystalline with good crystallinity. The copper sulfide ore used in the closed-circuit test was mined from a mine in Jiangxi province.

Table 1. Chemical composition of chalcopyrite (\%).

\begin{tabular}{ccccc}
\hline Mineral & Fe & S & Cu & Purity \\
\hline Chalcopyrite & 30.41 & 35.11 & 33.15 & 95.31 \\
\hline
\end{tabular}




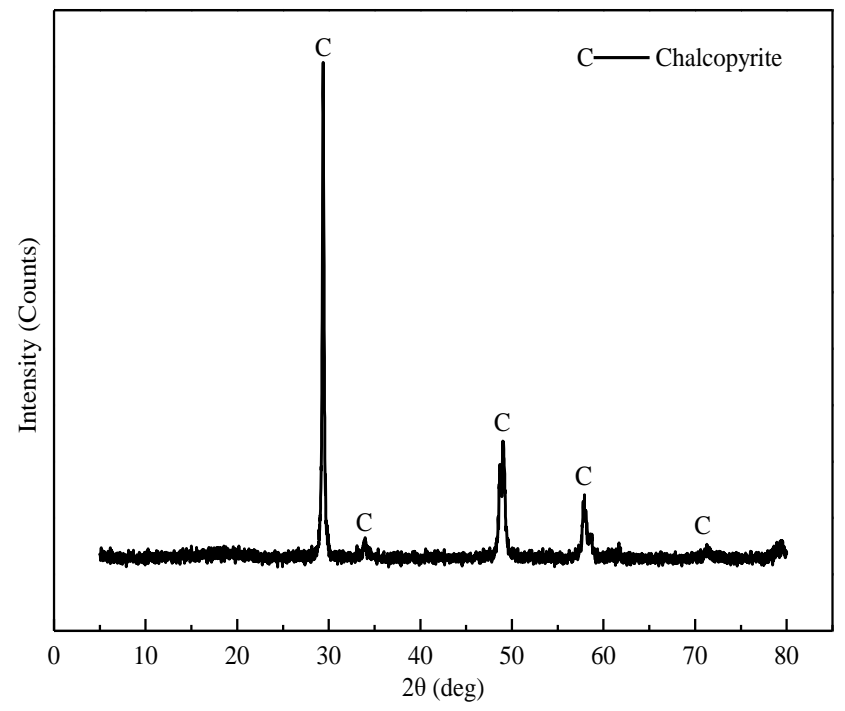

Figure 1. XRD pattern of chalcopyrite.

The sodium hydroxide (Sinopharm Chemical Reagent Co., Ltd., Shanghai, China), hydrochloric acid (Sinopharm Chemical Reagent Co., Ltd., Shanghai, China), and methyl isobutyl carbinol (MIBC) (Sinopharm Chemical Reagent Co., Ltd., Shanghai, China) used in monomineral tests were all analytically pure; the butyl xanthate (Zhuzhou Mingzhu Mineral Processing Reagent Co., Ltd., Hunan, China) was purified by acetone and petroleum ether, while deionized water was used as the test water. The lime (Zhuzhou Mingzhu Mineral Processing Reagent Co., Ltd., Hunan, China) used in the actual ore flotation tests was analytically pure, while the butylammonium black pill (Zhuzhou Mingzhu Mineral Processing Reagent Co., Ltd., Hunan, China) and terpineol oil (Zhuzhou Mingzhu Mineral Processing Reagent Co., Ltd., Hunan, China) used in the actual ore flotation tests were all industrially pure; tap water was also used in the tests.

\subsection{Research Methods}

\subsubsection{Magnetization of Butyl Xanthate}

A self-designed magnetization device was used for the pretreatment of the butyl xanthate solution, as shown in Figure 2. Butyl xanthate solution in the flume (Figure 2, (1)) was transferred to the magnetizer (5) composed of 15 pairs of $\mathrm{Nd}-\mathrm{Fe}-\mathrm{B}$ magnetic blocks and a stainless-steel shell by a pump (Figure 2, (4)). When the solution flowed through the magnetizer, it moved in a vertical direction and cut the magnetic line of induction repeatedly to achieve the purpose of magnetization.

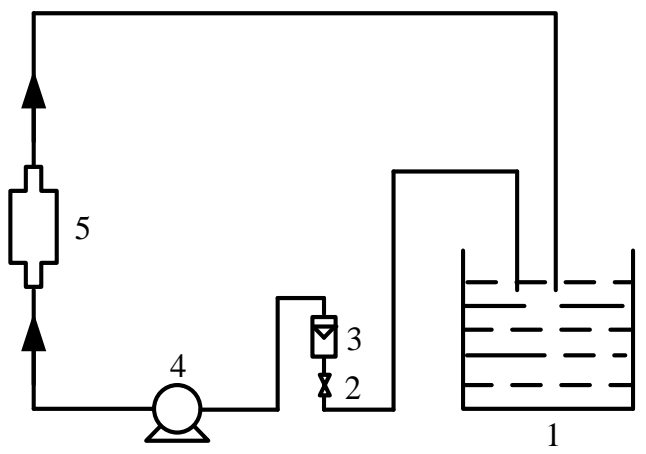

Figure 2. Schematic diagram of magnetization equipment system. 1, Flume; 2, saving flux valve; 3, flux meter; 4, pump; 5, magnetizer. 


\subsubsection{Monomineral Flotation Test}

A total of $2.0 \mathrm{~g}$ chalcopyrite and $40 \mathrm{~mL}$ deionized water was placed in the same beaker and cleaned with a KQ-100DV ultrasonic cleaner for $10 \mathrm{~min}$. After clarification, the upper suspension was poured, and the cleaned ore was washed into the $40 \mathrm{~mL}$ plexiglass tank of the XFG-II flotation machine by deionized water. According to the test requirements, the butyl xanthate solution was processed, and then the $\mathrm{pH}$ regulator, butyl xanthate, and MIBC were sequentially added to the plexiglass tank. Then, the tests were performed according to the flotation flowsheet in Figure 3. Finally, the concentrate was collected, dried, weighed, and the flotation recovery was calculated according to Formula (1) [18]. All tests were repeated 3 times, and the results are expressed as an average value. Each data point represents the average value in the figure and the error bar represents the standard deviation of each data point [19].

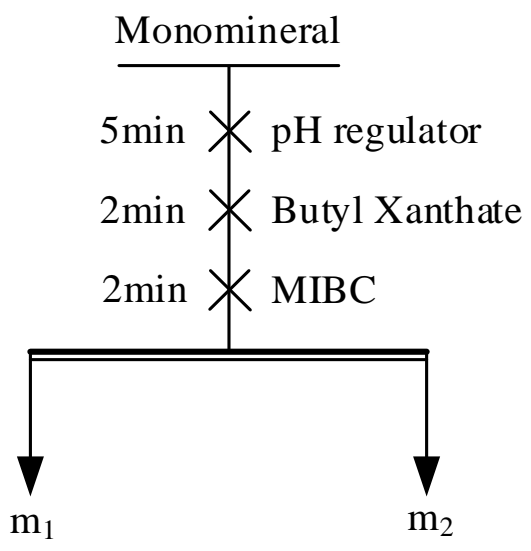

Figure 3. Flowsheet of flotation test.

Flotation recovery was calculated as follows:

$$
R=\frac{m_{1}}{m_{1}+m_{2}} \times 100 \%
$$

where $\mathrm{R}$ is the flotation recovery of minerals, $m_{1}$ is the quality of foam concentrates, and $m_{2}$ is the quality of tailings in the tank.

\subsubsection{Adsorption Test}

A UV-Vis spectrophotometer (WFZUV-2100, Shanghai Zhixin Instrument Co., Ltd., Shanghai, China) was used to conduct an absorbance test of the butyl xanthate solution. Different concentrations of unmagnetized and pre-magnetized butyl xanthate solutions were prepared separately, and the absorbance was measured at a wavelength of $300 \mathrm{~nm}[20,21]$. Then, the standard curves were drawn. Butyl xanthate was added to a beaker containing $1.0 \mathrm{~g}$ of ultrasonically cleaned chalcopyrite and $50 \mathrm{~mL}$ of deionized water and mixed well. After sufficient stirring, the supernatant was used to measure the absorbance. We combined the standard curves to calculate the concentration of the agents in the filtrate and calculate the adsorption amount of butyl xanthate on the surface of chalcopyrite according to Formula (2) [21]. Then, the specific surface area of the mineral was determined, and the adsorption density per unit area was calculated

$$
Q_{t}=\frac{\left(c_{0}-c_{t}\right) V}{W}
$$

where $c_{0}$ is the initial concentration of butyl xanthate solution $(\mathrm{mg} / \mathrm{L}), c_{t}$ is the butyl xanthate concentration of the supernatant at time $t(\mathrm{mg} / \mathrm{L}), W$ is the weight of chalcopyrite $(\mathrm{g}), V$ is the volume of butyl xanthate solution $(\mathrm{L})$, the adsorption capacity is $Q_{t}(\mathrm{mg} / \mathrm{g})$. 


\subsubsection{FTIR Test}

After samples were ground to $-5 \mu \mathrm{m}$, they were mixed in combinations of $0.5 \mathrm{~g}$, i.e., $0.5 \mathrm{~g}+20 \mathrm{~mL} 0.6 \mathrm{~g} / \mathrm{L}$ butyl xanthate solution and $0.5 \mathrm{~g}+20 \mathrm{~mL} 0.6 \mathrm{~g} / \mathrm{L}$ magnetized butyl xanthate solution, and filtered after stirring for $1 \mathrm{~h}$. Then, we filtered and rinsed the surface of the mineral with deionized water 2-3 times to eliminate the effect of excessive drugs on the mineral surface. After the sample was dried in a vacuum drying oven at $40{ }^{\circ} \mathrm{C}$, it was mixed with spectral grade $\mathrm{KBr}$ at a mass ratio of 1:100 [20] and pressed into a tablet with a grinding tool. An AVATAR 370 FTIR spectrometer (Thermo Fisher Scientific, Waltham, MA, USA) was used to test the spectra of the sample.

\subsubsection{Conductivity and Dissolved Oxygen Test}

The $30 \mathrm{mg} / \mathrm{L}$ butyl xanthate solution was magnetized as required, and the conductivity was measured on a DDS-11A digital display conductivity meter (Beijing Yanghai Weiye Technology Co., Ltd., Beijing, China); the dissolved oxygen content was measured on a JPB-607 portable dissolved oxygen meter (Beijing Yanghai Weiye Technology Co., Ltd., Beijing, China).

\subsubsection{Electrochemical Test}

In the electrochemical test, a saturated $\mathrm{KCl}$ solution was used as the electrolyte in a traditional three-electrode system. The platinum sheet electrode was used as the auxiliary electrode, the saturated calomel electrode was used as the reference electrode, and the chalcopyrite electrode with a surface area of $0.25 \mathrm{~cm}^{2}$ was used as the working electrode. The working electrode was prepared by cutting a chalcopyrite sample into a rectangular size of $5 \mathrm{~mm} \times 5 \mathrm{~mm} \times 10 \mathrm{~mm}$. The sample with a copper wire connected to a $5 \mathrm{~mm} \times 5 \mathrm{~mm}$ surface was mounted in a glass tube with an electrochemically inert epoxy resin, and one surface was exposed $[19,22]$.

Before each test, the sample was polished step-by-step with different types of metallographic sandpaper, then, polished to a mirror surface on a sample polishing machine, and rinsed with deionized water several times to update the working surface of the chalcopyrite electrode [23]. After the electrodes were connected by wires, the polarization curve of the chalcopyrite surface in the range of $-0.3-0.3 \mathrm{~V}$ was scanned and measured at a constant rate of $0.02 \mathrm{~V} / \mathrm{s}$.

\section{Results and Discussion}

3.1. Effect of Pre-Magnetized Butyl Xanthate on Flotation Behavior of Chalcopyrite Monomineral 3.1.1. Effect of Magnetization Intensity and Magnetization Time

In the conditions of $\mathrm{pH}=8-9$, a butyl xanthate dosage of $10 \mathrm{mg} / \mathrm{L}$, and a magnetization time of $10 \mathrm{~min}$, the effect of magnetization intensity on the flotation behavior of chalcopyrite was investigated. The test results are shown in Figure 4.

With an increase in the magnetization intensity, the flotation recovery of chalcopyrite showed an overall upward trend. When the magnetization intensity increased to $200 \mathrm{mT}$, the recovery of chalcopyrite reached a peak of $90.44 \%$, which was an increase of 3.3 percentage points as compared with the unmagnetized treatment (magnetization intensity $=0 \mathrm{mT}$ ), as shown in Figure 4. Subsequently, when the magnetization intensity was greater than $200 \mathrm{mT}$, the recovery of chalcopyrite remained balanced after a small decrease, but it was still higher than without magnetization. Thus, the optimal magnetization intensity was determined to be $200 \mathrm{mT}$. 


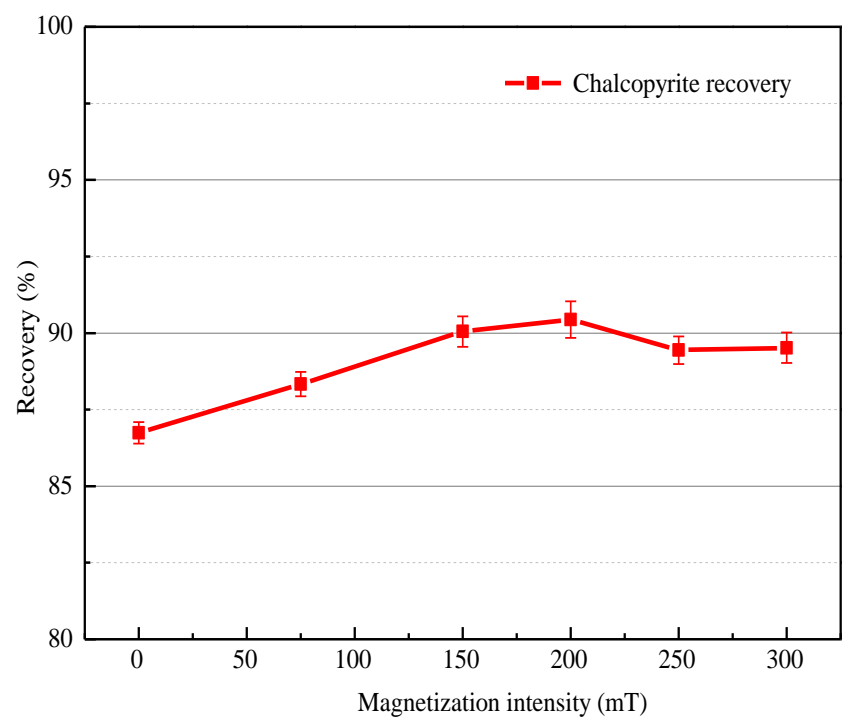

Figure 4. The relationship between the magnetization intensity and the recovery of chalcopyrite.

In the conditions of $\mathrm{pH}=8-9$, a magnetization intensity of $200 \mathrm{mT}$, and a butyl xanthate dosage of $10 \mathrm{mg} / \mathrm{L}$, the effect of magnetization time on the flotation behavior of chalcopyrite was investigated. The test results are presented in Figure 5.

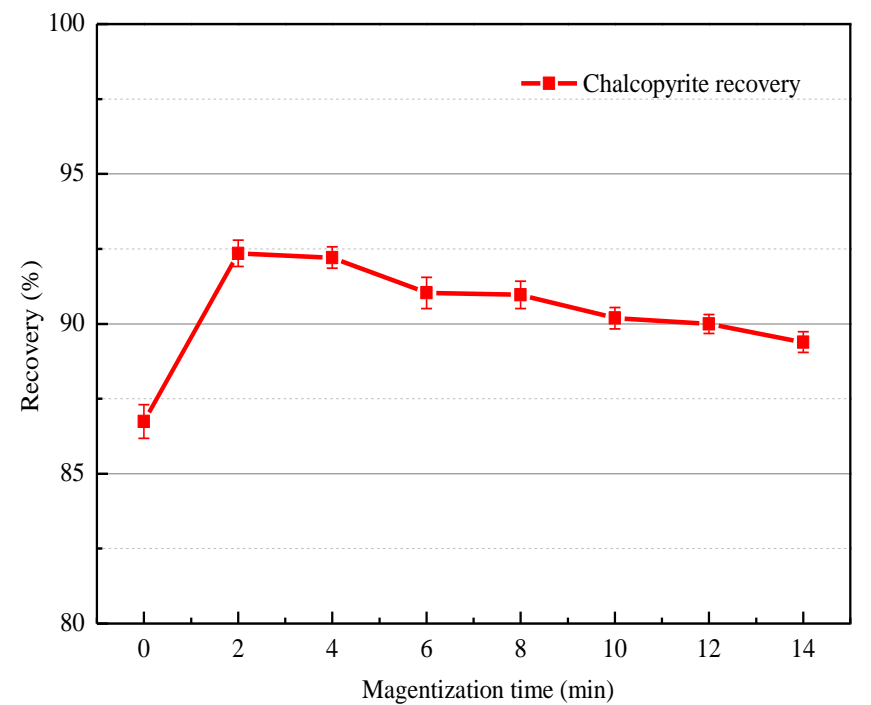

Figure 5. The relationship between the magnetization time and the recovery of chalcopyrite.

Figure 5 shows that the flotation recovery of chalcopyrite was $86.74 \%$ when butyl xanthate was not magnetized (magnetization time $=0 \mathrm{~min}$ ), and the flotation recovery of chalcopyrite remained at about $90 \%$ after the magnetization pretreatment of butyl xanthate. With an increase in the magnetization time, the recovery showed a slight downward trend, but was still greater than the recovery of chalcopyrite when butyl xanthate was not magnetized (magnetization time $=0 \mathrm{~min}$ ). When the magnetization time was greater than $10 \mathrm{~min}$, the recovery of chalcopyrite started to reach less than $90 \%$, and therefore, the magnetization time of $10 \mathrm{~min}$ was selected for subsequent tests.

\subsubsection{Effect of Butyl Xanthate Dosage}

Different concentrations of butyl xanthate were magnetized in a magnetization intensity of $200 \mathrm{mT}$ for $10 \mathrm{~min}$. In the conditions of pulp pH 8-9, unmagnetized and premagnetized butyl xanthate were used as collectors. The effect of butyl xanthate dosage on the recovery of chalcopyrite was investigated. The test results are shown in Figure 6. 


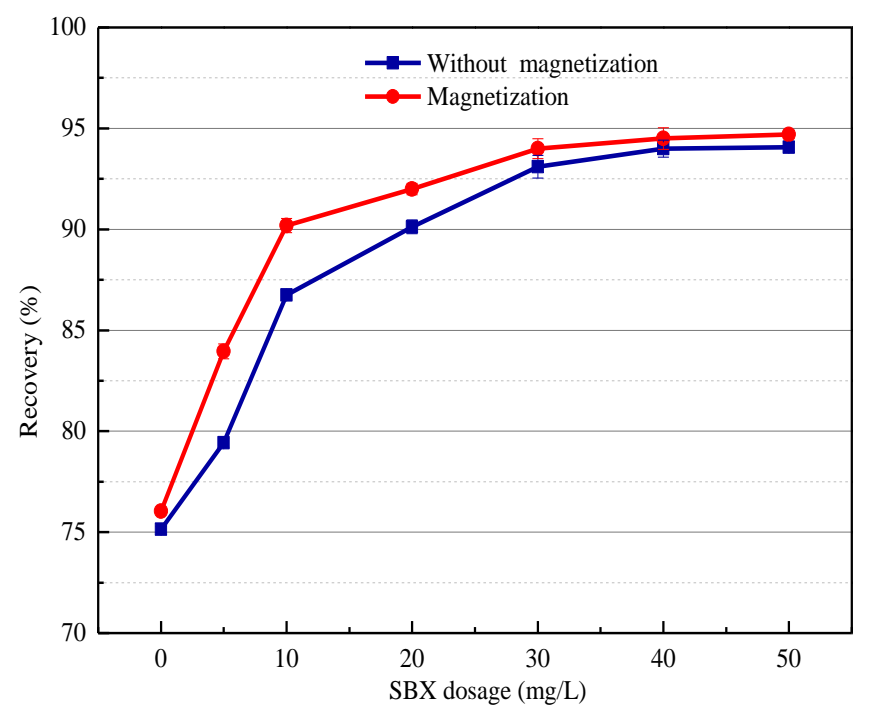

Figure 6. The relationship between butyl xanthate dosage and the recovery of chalcopyrite.

The flotation recovery of chalcopyrite increased first, and then, tended to balance out with an increase in butyl xanthate dosage. When the butyl xanthate dosage was $30 \mathrm{mg} / \mathrm{L}$, the flotation recovery of chalcopyrite tended toward the peak, and then, became stable in both magnetized and unmagnetized conditions (Figure 6). Thus, the optimal butyl xanthate dosage was $30 \mathrm{mg} / \mathrm{L}$. Figure 6 shows that without magnetization, the flotation recovery of chalcopyrite started to be greater than $90 \%$ until the butyl xanthate dosage was greater than $20 \mathrm{mg} / \mathrm{L}$. However, after magnetization pretreatment, $10 \mathrm{mg} / \mathrm{L}$ butyl xanthate could make the chalcopyrite recovery reach above $90 \%$, and the recovery increased by 0.5 to 4 percentage points as compared with the unmagnetized butyl xanthate. In the case of the same recovery of chalcopyrite, the magnetization pretreatment reduced the butyl xanthate dosage by 4-10 mg/L. It can be seen that the magnetization pretreatment of butyl xanthate improved the flotation recovery of chalcopyrite, and also reduced the amount of butyl xanthate.

\subsubsection{Effect of Pulp pH}

In the stated conditions, $30 \mathrm{mg} / \mathrm{L}$ unmagnetized butyl xanthate and $30 \mathrm{mg} / \mathrm{L}$ magnetized butyl xanthate (200 mT, $10 \mathrm{~min})$ were used as collectors. The effects of the pulp $\mathrm{pH}$ on the flotation of chalcopyrite were investigated. The test results are shown in Figure 7.

Figure 7 shows that, in the investigated $\mathrm{pH}$ range, the flotation recovery of chalcopyrite was more than $92 \%$ when the unmagnetized butyl xanthate was used as a collector. After the magnetization pretreatment of butyl xanthate, the recovery of chalcopyrite was significantly improved, which was an average increase of 2 percentage points as compared with unmagnetized butyl xanthate. Figure 7 shows that a change in the pulp $\mathrm{pH}$ had no obvious effect on the recovery of chalcopyrite. The recovery in neutral and weak alkaline conditions was slightly higher than other conditions. The relationship between the natural floatability of chalcopyrite and $\mathrm{pH}$ investigated by the researchers is consistent with the above results [24]. 


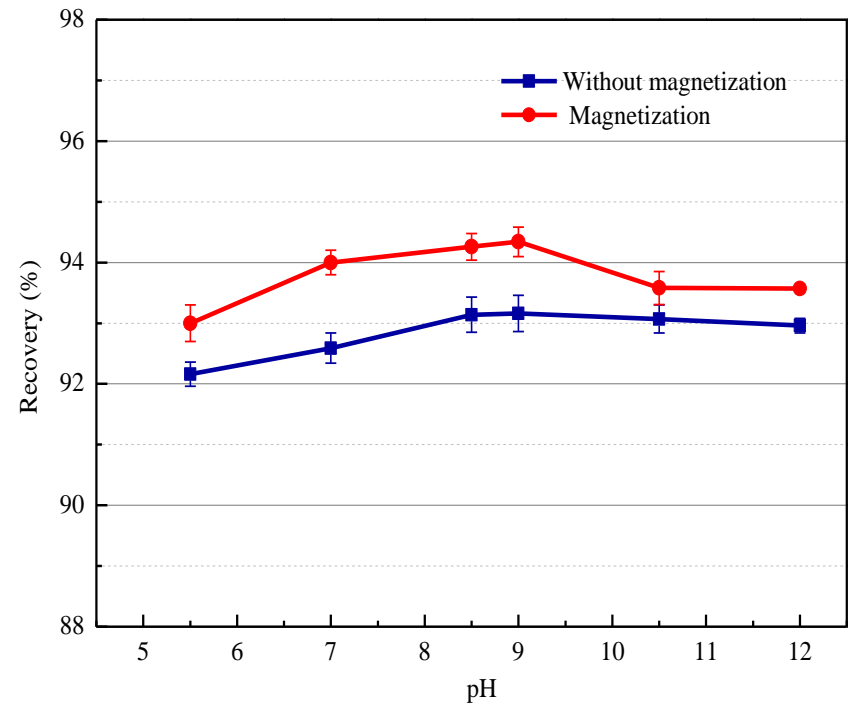

Figure 7. The relationship between $\mathrm{pH}$ and the recovery of chalcopyrite.

\subsection{Adsorption Test}

To investigate the effect of magnetization pretreatment on the adsorption of butyl xanthate on the chalcopyrite surface, butyl xanthate was divided into unmagnetized and magnetized solutions, and the adsorption density of butyl xanthate on chalcopyrite surface was measured at different concentrations. The results are presented in Figure 8.

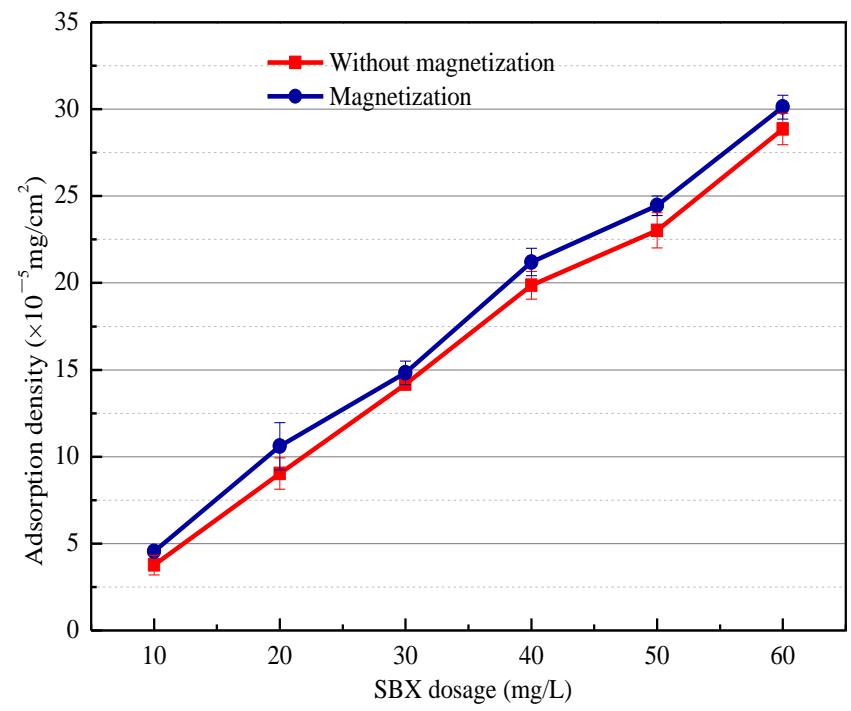

Figure 8. The relationship between butyl xanthate dosage and adsorption density.

Figure 8 shows that, with an increase in butyl xanthate dosage, the chalcopyrite adsorption density for the two groups of butyl xanthate solutions presented an increasing trend, which was basically consistent with the flotation test results. It is not difficult to see that, for the same dosage of butyl xanthate, the adsorption density of butyl xanthate with magnetization on the chalcopyrite surface was higher than that without magnetization. This indicated that magnetization promoted the adsorption of butyl xanthate on the chalcopyrite surface. Deng Bo et al. [25] researched the effect of magnetic field on the physical and chemical properties of water, and their results showed that magnetization could deform and twist the hydrogen bonds in water, thereby, dissociating water from agglomerate macromolecules $\left(\mathrm{H}_{2} \mathrm{O}\right)_{n}$ into many single biomolecules $\left(\mathrm{H}_{2} \mathrm{O}\right)_{2}$. It is speculated that when the butyl xanthate solution is magnetized, the positive and negative ions and polar molecules in the solution are affected by the Lorentz force and move in 
the opposite direction. As a result, the hydrogen bonds in the solution are broken, the dispersion of molecules and ions is increased, the contact probability between the reagent and the mineral is increased, and the adsorption capacity is increased.

\subsection{FTIR Analysis}

FTIR testing and analysis of chalcopyrite and chalcopyrite adsorbed with butyl xanthate were conducted to further reveal the mechanism of magnetization pretreatment on the adsorption of butyl xanthate on the chalcopyrite surface. The infrared spectra are shown in Figure 9.

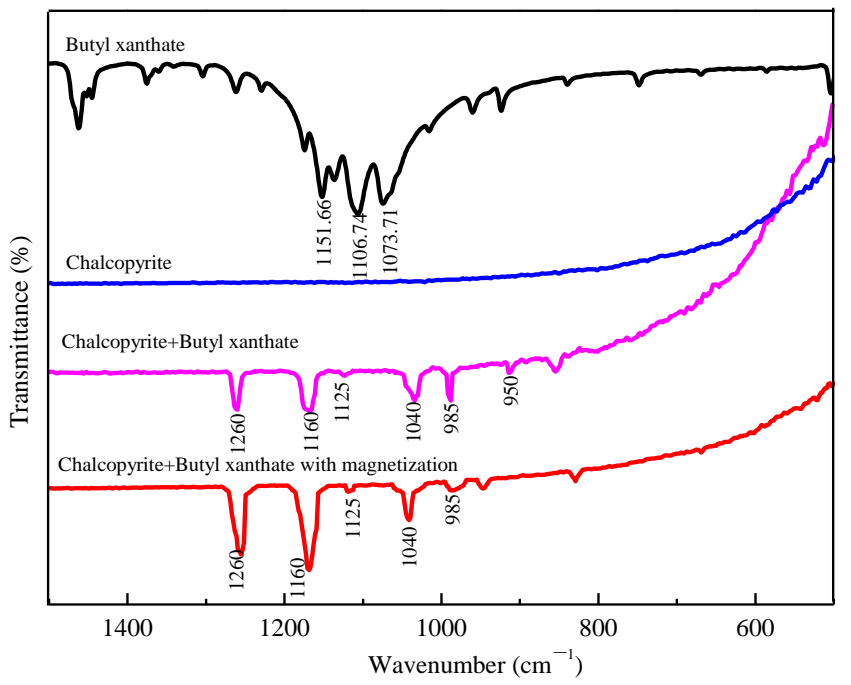

Figure 9. Infrared spectra for butyl xanthate, chalcopyrite, chalcopyrite+ butyl xanthate, and chalcopyrite+ butyl xanthate with magnetization.

In Figure 9, the main visible infrared absorption peaks of butyl xanthate are a C-O-C stretching vibration peak at $1151.66 \mathrm{~cm}^{-1}$ and a $C=S$ stretching vibration peak at $1106.74 \mathrm{~cm}^{-1} \sim 1073.71 \mathrm{~cm}^{-1}[26,27]$. Fresh chalcopyrite surface has no obvious characteristic peak in the investigated wavelength range. As can be seen from Figure 9, after the adsorption of unmagnetized butyl xanthate on the chalcopyrite surface, the characteristic absorption peak of dixanthate at $1260 \mathrm{~cm}^{-1}$ and that of cuprous xanthate at $1160 \mathrm{~cm}^{-1}$ appeared on the chalcopyrite surface, indicating that co-adsorption of cuprous xanthate and dixanthate occurred on the surface of chalcopyrite [28]. The magnetization pretreatment of butyl xanthate did not change the position of characteristic absorption peaks on the chalcopyrite surface, but the intensity of each absorption peak increased significantly. This may be because the butyl xanthate was fully dissociated in solution after magnetization pretreatment and the reaction activity was enhanced, which contributed to the interaction between effective functional groups and mineral particles and promoted the formation of more hydrophobic substances on the chalcopyrite surface.

\subsection{The Mechanism of Magnetization Pretreatment to Promote the Selective Adsorption of Butyl Xanthate}

In order to investigate the effect of magnetization treatment on the physical and chemical properties of butyl xanthate solution, and to reveal the deeper mechanism of magnetization treatment of butyl xanthate to improve the flotation behavior, the dissolved oxygen content and the conductivity of the solution were tested. The test results are shown in Figures 10 and 11. 


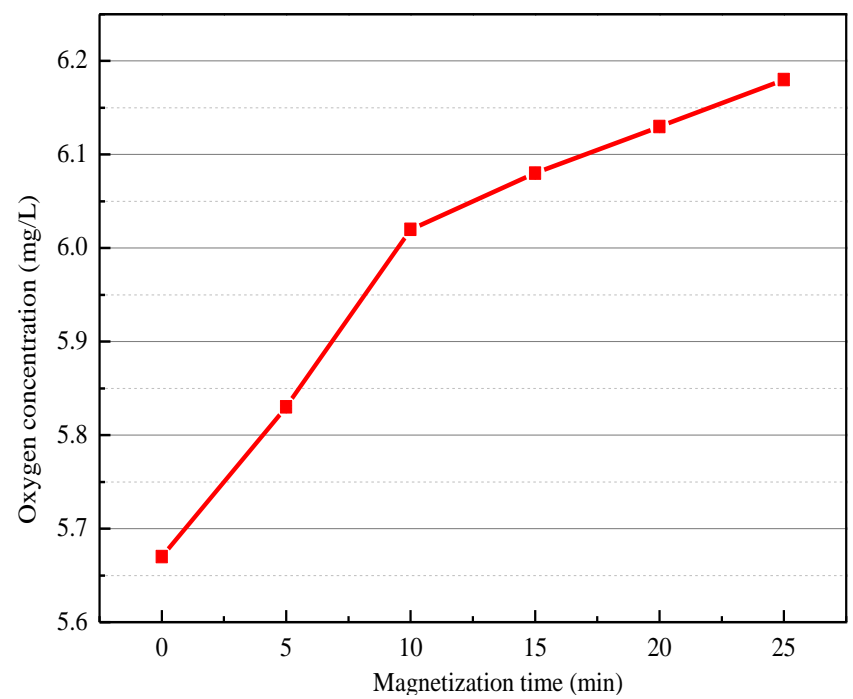

Figure 10. The relationship between oxygen concentration and magnetization time.

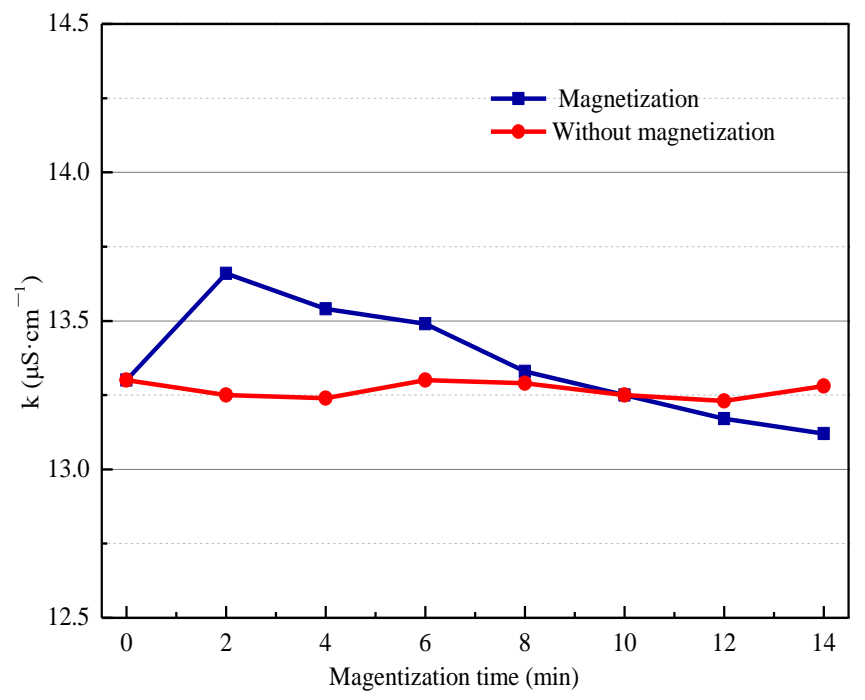

Figure 11. The relationship between conductivity and magnetization time.

Figure 10 shows the relationship between dissolved oxygen concentration and magnetization time. The content of dissolved oxygen was lower when it was not magnetized, only $5.67 \mathrm{mg} / \mathrm{L}$. After magnetization, the dissolved oxygen content increased, and it was positively correlated with the magnetization time, as shown in Figure 10. Studies have shown that xanthate is easily oxidized to double xanthate when the oxygen content is high, as shown in Formula (3) [29]. Jian Baixi et al. [30] studied the effects of $\mathrm{O}_{2}, \mathrm{CO}_{2}$, and their mixtures on the decomposition kinetics of xanthate in water and found that both gases could accelerate the oxidation of xanthate to double xanthate. The magnetization pretreatment increased the content of dissolved oxygen in the solution, prompting Formula (3) to proceed to the right and increasing the content of butyl bixanthate in the solution. The selectivity of double xanthate as a collector was better than that of xanthate, which was especially obvious in copper sulfide ore.

$$
4 \mathrm{ROCSS}^{-}+\mathrm{H}_{2} \mathrm{O}+\mathrm{O}_{2} \rightarrow 2(\mathrm{ROCSS})_{2}+4 \mathrm{OH}^{-}
$$

In the conditions of butyl xanthate concentration of $30 \mathrm{mg} / \mathrm{L}$ and magnetic field strength of $200 \mathrm{mT}$, the relationship between magnetization time and solution conductivity is shown in Figure 11. As the magnetization time increased, the conductivity of the unmagnetized butyl xanthate solution was basically stable at about $13.25 \mu \mathrm{S} \cdot \mathrm{cm}^{-1}$. However, after 
magnetization pretreatment, the conductivity of butyl xanthate solution showed a trend of increasing first, and then, decreasing. It is speculated that the reasons for the increase in conductivity may be: (1) Under the action of a magnetic field, the hydrogen bonds in the solution are twisted and broken, which changes the structure of water and increases the conductivity. (2) Magnetization promotes the dissociation of butyl xanthate in water, which increases the number of free ions in the solution, intensifies thermal motion, and increases electrical conductivity. As the magnetization time increases, the conductivity of the solution reaches a peak, and then decreases. This may be because the oxygen content in the solution increases (as shown in Figure 9), and butyl xanthate is gradually oxidized to butyl bixanthate. Butyl bixanthate is an oily liquid which it is not easily dissociated in water, thereby, reducing the number of free ions in the solution and decreasing the conductivity.

\subsection{Electrochemical Property Analysis}

The essence of the interaction between collector and target minerals is that collectors form as hydrophobic film on the mineral's surface, improving the floatability of the target mineral, and thus, achieving the purpose of separation from the gangue mineral. Its reaction formulas are shown in Equations (4) and (5). However, this layer of hydrophobic film with poor conductivity covers the surface of the sulfide ore with semiconductor properties, which will hinder the electrochemical corrosion of the surface of sulfide ore. Thus, the electrochemical properties of the chalcopyrite surface in different $\mathrm{pH}$ conditions were studied from the point of corrosion. Figure 12 shows the polarization curves of chalcopyrite in unmagnetized and pre-magnetized butyl xanthate solution. The electrochemical parameters after fitting are shown in Table 2.

$$
\begin{gathered}
M S+2 X^{-} \rightarrow M S_{2}+S^{0}+2 e \\
2 X^{-} \rightarrow X_{2}+2 e
\end{gathered}
$$
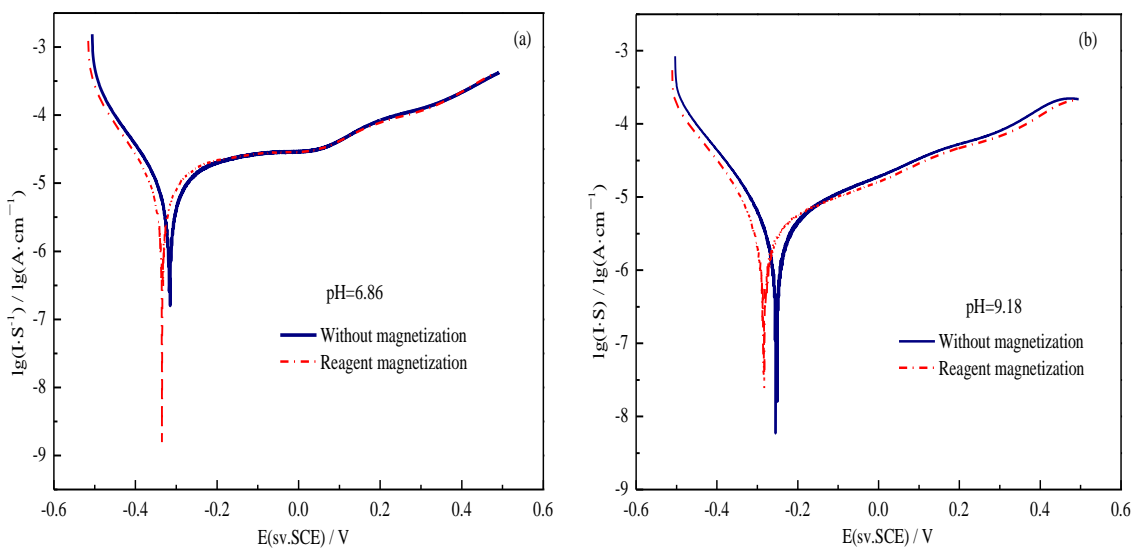

Figure 12. The effect of magnetization on the polarization curve of chalcopyrite at $\mathrm{pH}=6.86$ (a) and $\mathrm{pH}=9.18(\mathbf{b})$.

Table 2. Electrolytic corrosion parameters of chalcopyrite surface in different $\mathrm{pH}$ values.

\begin{tabular}{cccc}
\hline $\mathbf{p H}$ & Condition & Ecorr $(\mathbf{m V})$ & Icorr $\left(\boldsymbol{\mu A} \cdot \mathbf{c m}^{-2}\right)$ \\
\hline \multirow{2}{*}{6.86} & Without magnetization & -0.316 & 9.700 \\
& Reagent magnetization & -0.335 & 9.674 \\
\multirow{2}{*}{9.18} & Without magnetization & -0.253 & 4.727 \\
& Reagent magnetization & -0.284 & 4.261 \\
\hline
\end{tabular}

The level of corrosion voltage reflects the degree of corrosion of electrode materials, while the corrosion current density can characterize the speed of corrosion reaction of electrode materials [31,32]. The results have shown that in different $\mathrm{pH}$ conditions, the 
corrosion potential of the chalcopyrite surface decreased when butyl xanthate was magnetized as compared with that without magnetization. The corrosion current density also decreased gradually, by 0.026 and $0.466 \mu \mathrm{A} \cdot \mathrm{cm}^{-2}$ at $\mathrm{pH}$ values of 6.86 and 9.18 , respectively. It indicated that magnetization pretreatment made butyl xanthate more easily adsorbed on the chalcopyrite surface and formed a hydrophobic film, which reduced the corrosion potential and current density of the chalcopyrite surface and inhibited the electrochemical corrosion process on the chalcopyrite surface.

\subsection{Flotation Test of Actual Copper Sulfide Ore}

Deng Xiangxiang et al. [33] magnetized water in a scheelite flotation project. The results showed that this process could improve the effect of chemicals and minerals, increasing the grade of tungsten coarse concentrate by $0.92 \%$ and the recovery rate by $4.43 \%$; therefore, demonstrated that magnetic flotation has great application potential. To verify the effect of pre-magnetized butyl xanthate on actual copper sulfide ore flotation, in the same technological flow and other parameters, unmagnetized and pre-magnetized butyl xanthate were used as collectors to conduct a small-scale closed-circuit flotation test of actual copper sulfide ore. The main constituent minerals of the ore are pyrite and chalcopyrite, followed by molybdenite, as well as a small amount of arsenite, bornite, etc. The chemical multi-element analysis is shown in Table 3, the flowsheet is shown in Figure 13, and the test results are shown in Table 4.

Table 3. Chemical multi-element analysis (\%).

\begin{tabular}{cccccccccccccc}
\hline Element & $\mathbf{C u}$ & $\mathbf{P b}$ & $\mathbf{Z n}$ & $\mathbf{M o}$ & $\mathbf{S}$ & $\mathbf{F e}$ & $\mathrm{As}$ & $\mathbf{A l}_{\mathbf{2}} \mathbf{O}_{3}$ & $\mathrm{SiO}_{2}$ & $\mathbf{C a}$ & $\mathbf{M g O}$ & $\mathbf{A u}$ & $\mathbf{A g}{ }^{*}$ \\
\hline Content & 0.34 & 0.003 & 0.0032 & 0.006 & 3.18 & 4.72 & 0.0018 & 14.23 & 62.37 & 0.93 & 0.66 & 0.26 & 0.79 \\
\hline
\end{tabular}

Marked with "**" means its unit is g.t ${ }^{-1}$.

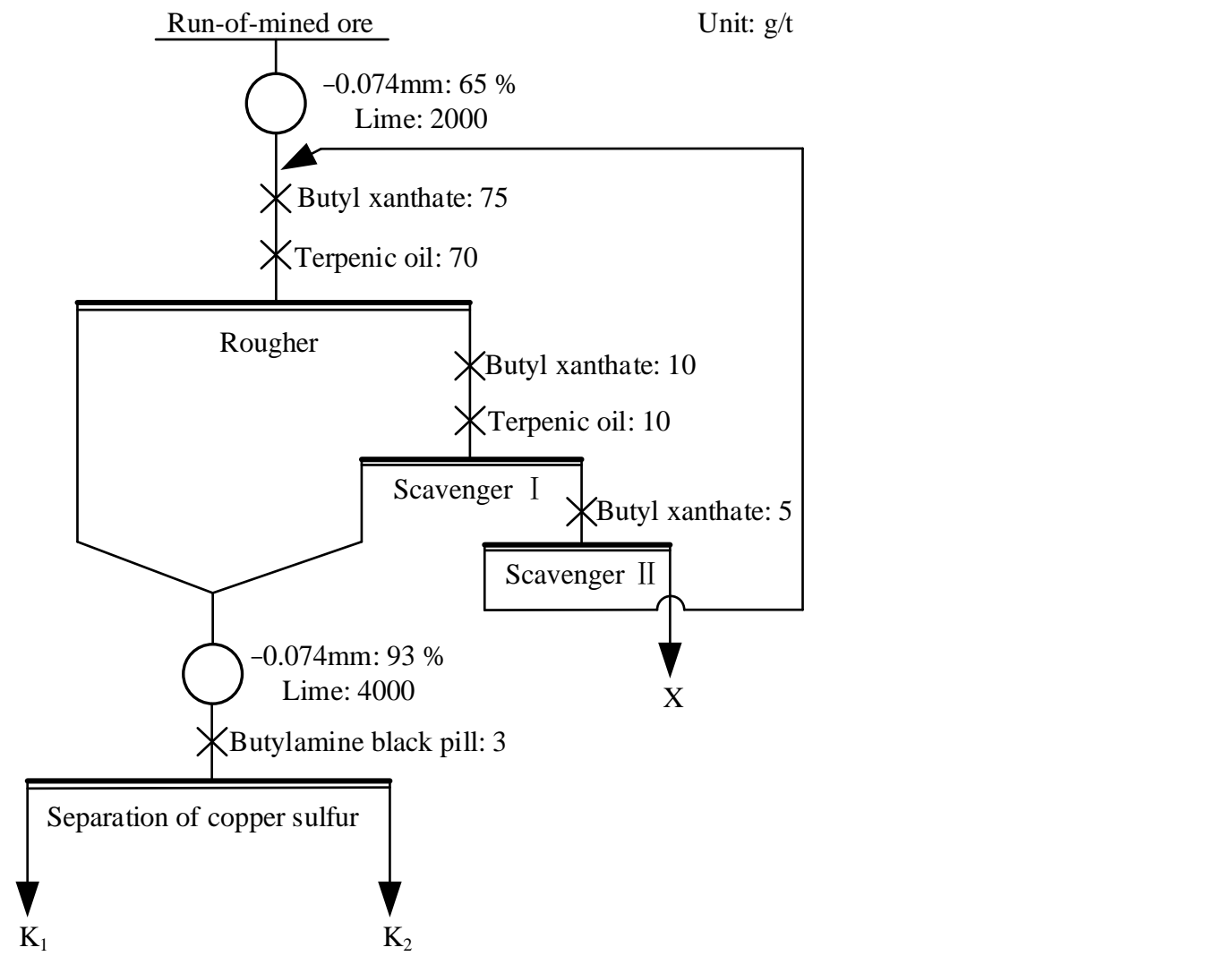

Figure 13. Flowsheet of closed-circuit test. 
Table 4. The results of closed-circuit test.

\begin{tabular}{|c|c|c|c|c|c|c|}
\hline \multirow{2}{*}{ Condition } & \multirow{2}{*}{ Product } & \multirow{2}{*}{ Yield (\%) } & \multicolumn{2}{|c|}{ Grade (\%) } & \multicolumn{2}{|c|}{ Recovery (\%) } \\
\hline & & & $\mathrm{Cu}$ & S & $\mathrm{Cu}$ & $S$ \\
\hline \multirow{4}{*}{$\begin{array}{c}\text { Without } \\
\text { magnetization }\end{array}$} & $\mathrm{K}_{1}$ & 3.39 & 7.92 & 11.24 & 79.01 & 11.98 \\
\hline & $\mathrm{K}_{2}$ & 6.38 & 0.32 & 37.34 & 6.00 & 74.91 \\
\hline & $x$ & 90.43 & 0.056 & 0.46 & 14.99 & 13.10 \\
\hline & Run-of-mined ore & 100.00 & 0.34 & 3.18 & 100.00 & 100.00 \\
\hline \multirow{4}{*}{$\begin{array}{c}\text { Reagent } \\
\text { magnetization }\end{array}$} & $\mathrm{K}_{1}$ & 3.58 & 7.79 & 9.49 & 82.07 & 10.68 \\
\hline & $\mathrm{K}_{2}$ & 6.06 & 0.32 & 40.80 & 5.70 & 77.75 \\
\hline & $x$ & 90.36 & 0.046 & 0.41 & 12.23 & 11.57 \\
\hline & Run-of-mined ore & 100.00 & 0.34 & 3.18 & 100.00 & 100.00 \\
\hline
\end{tabular}

According to Table 4, the copper recovery of the copper concentrate was $82.07 \%$ when pre-magnetized butyl xanthate was used as the collector, which was 3.06 percentage points higher than that without magnetization. The grade of sulfur in copper concentrate also decreased from $11.24 \%$ to $9.49 \%$. Therefore, the magnetization pretreatment of butyl xanthate not only improved the recovery of copper concentrate but also improved the quality of copper concentrate. The sulfur grade in the sulfur concentrate increased from $37.34 \%$ to $40.80 \%$, the sulfur recovery increased by nearly 3 percentage points, and the copper content was also relatively reduced. The closed-circuit test results showed that magnetization pretreatment of butyl xanthate could enhance the separation effect of copper and sulfur minerals in a copper sulfide ore and could reduce the mutual content of copper and sulfur concentrates.

\section{Conclusions}

Using $30 \mathrm{mg} / \mathrm{L}$ pre-magnetized butyl xanthate as a collector increased chalcopyrite recovery by nearly two percentage points. At the same recovery time, magnetization reduced the butyl xanthate dosage by $4-10 \mathrm{mg} / \mathrm{L}$.

The magnetization pretreatment increased the oxygen content in the solution, promoted the oxidation of the butyl xanthate solution into double xanthate, and adsorbed on the mineral surface, increasing the flotation selectivity of the collector.

The electrochemical test results showed that magnetized butyl xanthate decreased the corrosion potential and current density of the chalcopyrite surface and inhibited the self-corrosion process of chalcopyrite surface.

The flotation test results of actual copper sulfide ore showed that after magnetization of butyl xanthate solution, copper concentrate recovery increased by 3.06 percentage points, while sulfur concentrate recovery increased by 3 percentage points. The quality of the copper and sulfur concentrates was markedly improved.

Author Contributions: Conceptualization, T.Q.; data curation, L.Y.; investigation, L.C.; project administration, T.Q. and H.Y.; resources, H.Z. and X.L.; writing—original draft, L.Y.; writing—review and editing, H.Y. All authors have read and agreed to the published version of the manuscript.

Funding: This work was support by the National Natural Science Foundation of China (no. 51974138), the Natural Science Foundation of Jiangxi Province (20202BABL214022), the Open Foundation of State Key Laboratory of Mineral Processing (BGRIMM-KJSKL-2020-21), and the Research Startup Funding Project of JXUST (jxxjbs19019 and jxxjbs19020).

Data Availability Statement: Not applicable.

Acknowledgments: The authors gratefully acknowledge the Laboratory of Resource and Environmental Engineering of Jiangxi University of Science and Technology, for providing the experimental conditions.

Conflicts of Interest: The authors declare no conflict of interest. 


\section{References}

1. Kong, Y.; Li, F.; Jia, Q.; Li, G. Application of Magnetization Treatment in Flotation. J. Phys. Conf. Ser. 2021, 1748, 062005. [CrossRef]

2. Qiu, T.S.; Cui, L.F.; Fang, X.H. Progress in the Application Research of Magnetic Treatment Technology in Mineral Processing. Met. Min. 2008, 12, 1-4, 8. (In Chinese)

3. Li, F.J.; Kong, Y.R.; Jia, Q.M.; Li, G.F. Mechanism of Magnetization Effect on Flotation and Its Application in Flotation. MulTipurpose Util. Miner. Resour. 2021, 3, 120-126. (In Chinese)

4. Qiu, T.S.; Cui, L.F.; Fang, X.H. Effect of magnetization on flotation reagents and process. Chin. J. Nonferrous Met. 2009, 7, 1338-1344. (In Chinese)

5. Qiu, T.S.; Yin, Y.F.; Fang, X.H.; Luo, X.P. Effects of Magnetization Treatment on Pyrite Depression and Its Mechanism Probing. Multipurp. Util. Miner. Resour. 2001, 6, 5-8. (In Chinese)

6. Wang, Z.; He, T.; Li, H.; Wang, Y. Influence of magnetized water on molybdenite flotation and its mechanism. Environ. Technol. 2020, 43, 107-115. [CrossRef]

7. Wan, H.; Qu, J.; Li, H.; He, T.; Bu, X.; Yang, W. A Novel Method for Improving Low-Temperature Flotation Performance of Nonpolar Oil in the Molybdenite Flotation. Minerals 2019, 9, 609. [CrossRef]

8. Xiang, J.; Zhou, W.B.; Xiong, W.; Cheng, H.; Zhu, Z.Q.; Xu, M. Study on the Effect and Mechanism of Magnetization on Fine Grain Hematite Flotation. Met. Min. 2020, 8, 76-82. (In Chinese)

9. Manouchehri, H.-R. Magnetic conditioning of sulfide minerals to improve recovery of fines in flotation-A plant practice. Miner. Met. Process. 2018, 35, 46-54. [CrossRef]

10. Li, Y.; Kawashima, N.; Li, J.; Chandra, A.P.; Gerson, A.R. A review of the structure, and fundamental mechanisms and kinetics of the leaching of chalcopyrite. Adv. Colloid Interface Sci. 2013, 197-198, 1-32. [CrossRef]

11. Wang, J.B.; Li, X.; Gu, S.L. Comparative Analysis of Copper Resource Supply and Demand Development Trend in China and the United States. Adv. Mater. Res. 2014, 962-965, 1953-1960. [CrossRef]

12. Han, G.; Wen, S.; Wang, H.; Feng, Q. Interaction mechanism of tannic acid with pyrite surfaces and its response to flotation separation of chalcopyrite from pyrite in a low-alkaline medium. J. Mater. Res. Technol. 2020, 9, 4421-4430. [CrossRef]

13. Liu, Q.Y.; Wang, A.J.; Chen, Q.S. China.s copper resources supply the challenge and countermeasures. In Applied Mechanics and Materials; Trans Tech Publications Ltd.: Bäch, Switzerland, 2013; Volume 295, pp. 3089-3093.

14. Sarquís, P.; Menéndez-Aguado, J.; Mahamud, M.M.; Dzioba, R. Tannins: The organic depressants alternative in selective flotation of sulfides. J. Clean. Prod. 2014, 84, 723-726. [CrossRef]

15. Liu, R.-Z.; Qin, W.; Jiao, F.; Wang, X.-J.; Pei, B.; Yang, Y.-J.; Lai, C.-H. Flotation separation of chalcopyrite from galena by sodium humate and ammonium persulfate. Trans. Nonferrous Met. Soc. China 2016, 26, 265-271. [CrossRef]

16. Ma, X.; Xia, L.Y.; Wang, S.; Zhong, H.; Jia, H. Structural Modification of Xanthate Collectors to Enhance the Flotation Selec-tivity of Chalcopyrite. Ind. Eng. Chem. Res. 2017, 56, 6307-6316. [CrossRef]

17. Ma, X.; Wang, S.; Zhong, H. Effective production of sodium isobutyl xanthate using carbon disulfide as a solvent: Reaction kinetics, calorimetry and scale-up. J. Clean. Prod. 2018, 200, 444-453. [CrossRef]

18. Cao, Z.; Cao, Y.; Qu, Q.; Zhang, J.; Mu, Y. Separation of bastnäsite from fluorite using ethylenediamine tetraacetic acid as depressant. Miner. Eng. 2019, 134, 134-141. [CrossRef]

19. Wang, X.; Qin, W.; Jiao, F.; Wu, J. The influence of galvanic interaction on the dissolution and surface composition of galena and pyrite in flotation system. Miner. Eng. 2020, 156, 106525. [CrossRef]

20. Qin, W.-Q.; Wang, X.-J.; Ma, L.-Y.; Jiao, F.; Liu, R.-Z.; Gao, K. Effects of galvanic interaction between galena and pyrite on their flotation in the presence of butyl xanthate. Trans. Nonferrous Met. Soc. China 2015, 25, 3111-3118. [CrossRef]

21. Zhang, C.; He, T.; Li, H.; Bu, X. Adsorption Thermodynamics and Kinetics of Xanthate at Chalcopyrite Surface Based on Ultraviolet Spectrophotometry. Spectrosc. Spectr. Anal. 2019, 39, 3172-3178. (In Chinese)

22. $\mathrm{Mu}, \mathrm{Y}$; Peng, Y.; Lauten, R.A. The galvanic interaction between chalcopyrite and pyrite in the presence of lignosulfonate-based biopolymers and its effects on flotation performance. Miner. Eng. 2018, 122, 91-98. [CrossRef]

23. Hicyilmaz, C.; Altun, N.E.; Ekmekci, Z.; Gokagac, G. Quantifying hydrophobicity of pyrite after copper activation and DTPI addition under electrochemically controlled conditions. Miner. Eng. 2004, 17, 879-890. [CrossRef]

24. Abramov, A.A. Technology of Processing and Enrichment of Non-Ferrous Metal Ores; Publishing House of the Moscow State Mining University: Moscow, Russia, 2005.

25. Peng, X.F.; Deng, B. Changes of features of water under action of magnetic-field and its mechanism of change. J. At. Mol. Phys. 2007, 24, 281-290.

26. Wei, Q.; Dong, L.; Jiao, F.; Qin, W.; Pan, Z.; Cui, Y. The synergistic depression of lime and sodium humate on the flotation separation of sphalerite from pyrite. Miner. Eng. 2021, 163, 106779. [CrossRef]

27. Wang, X.; Liu, J.; Zhu, Y.; Han, Y. Adsorption and depression mechanism of an eco-friendly depressant PCA onto chalcopyrite and pyrite for the efficiency flotation separation. Colloids Surf. A Physicochem. Eng. Asp. 2021, 620, 126574. [CrossRef]

28. Zhu, Y.; Zhu, J. The Chemical Principle of Flotation Reagent; Central South University of Technology Press: Changsha, China, 1996; pp. 10-30. (In Chinese)

29. Zhu, Y.S. Chemistry Principles of Flotation Reagents; Central South University of Technology Press: Changsha, China, 1996; pp. 13-17. (In Chinese)

30. Jian, B.X. Flotation Reagents; Metallurgical Industry Press: Beijing, China, 1981; pp. 17-21. 
31. Hu, Y.; Sun, W.; Wang, D. Corrosive Electrochemistry of Oxidation-Reduction of Sulphide Minerals. In Electrochemistry of Flotation of Sulphide Minerals; Springer: Berlin/Heidelberg, Germany, 2009; pp. 167-200. [CrossRef]

32. Rybalka, K.V.; Beketaeva, L.A.; Davydov, A.D. Estimation of corrosion current by the analysis of polarization curves: Electrochemical kinetics mode. Russ. J. Electrochem. 2014, 50, 108-113. [CrossRef]

33. Deng, X.X.; Liao, D.H. Study on Magnetic Flotation Technique of a Refractory Scheetite. Min. R D 2015, 35, 55-59. (In Chinese) 